\title{
Large Breach Penalties and Managers' Incentives to Invest Inside or Outside Firms
}

\author{
by \\ NiCOLA MECCHERI*
}

\begin{abstract}
April 27, 2009
In this paper, managers' incentives to invest in firms' specific activities ("internal" investments) are compared with those to realize activities to increase their alternative market opportunities ("external" investments), when managerial contract establishes a large breach penalty in the event of employment termination and wage bargaining occurs according to the outside option principle. First, it is shown that internal and external investments are "incentive" substitutes from the manager's viewpoint. Furthermore, large breach penalties against firms reduce managers' incentives to invest inside (and raise those to invest outside) the incumbent employment relationship. By contrast, large breach penalties against managers perform better in enhancing managers' firm-specific investments. (JEL: G30, J24, J38, J41)
\end{abstract}

\section{Introduction}

A rationale often argued for the presence in managerial contracts of privately stipulated clauses, which make firms pay their managers large breach penalties in the event of contract termination, refers to the role such penalties can play in protecting managers' firm-specific investments in BECKER's [1964] sense (i.e. investments only valued inside the manager-firm employment relationship) and, consequently, in motivating managers to make such types of investments (e.g. WiLliamson [1984]). ${ }^{1}$ The logic goes as follows: since a large breach penalty reduces the probability of a manager being dismissed, by making such a possibility more expensive for the firm, managers feel their position inside the firm is more protected and this should encourage them to make investments specific

*This paper has benefited greatly from comments and suggestions by Emilio Barucci, Francesco Filippi, Mario Morroni and an anonymous referee. I would like to thank also participants at EALE 2008 (Amsterdam), AIEL 2008 (Brescia), SIE 2008 (Perugia) and seminar attendants at University of Pisa for useful remarks. Usual disclaimers apply.

${ }^{1} \mathrm{~A}$ variant in managerial contracts to breach penalties is represented by so-called "golden parachutes", i.e. large severance payments made to top executives only when their corporations are merged or taken over. Williamson states that "golden parachutes ought to vary directly with the extent of the firm-specific investment that a manager has placed at risk" (WILLIAMSON [1984, p. 1218]). 
to that firm. Alternatively, since the penalty may operate as a compensation for the loss managers suffer from dismissal (since they possess firm-specific skills), it should reduce managers' reluctance to make firm-specific investments when there is the possibility of dismissal. ${ }^{2}$

However, neither of the above arguments seem to take into account that real incentives to make specific (as well as general) investments are not provided by job protection or dismissal compensation, but they hinge on the possibility for the investor to reap adequate return from the investment. In other words, the manager will fully realize a firm-specific investment only if he/she can capture, through a wage increase, the full return of the investment. Thus the proper issue is whether the presence in managerial contracts of a large breach penalty from the firm to the manager can ensure that the latter is able to reap the return of investments specific to the firm.

This paper analyzes this issue in a framework in which a manager and a firm (or a board of directors) negotiate over a wage after the manager has chosen how much to invest in an action that increases the firm's productivity (but that has no value outside the current employment relationship). In addition, before wage bargaining and together with the choice of investment that increases the firm's productivity, the manager may choose (how much) to invest also outside the employment relationship in order to increase his/her alternative market opportunities.

The results of the paper can be summarized as follows. A preliminary finding (which nonetheless plays an important role in the main results that follow) is that even if no technology or cost interaction exists between internal and external investments, they are "incentive" substitutes from the manager's viewpoint. That is, increasing the level of one type of investment reduces (via wage bargaining) the incentives to realize the other type.

Secondly, it is shown that a managerial contract including a large breach penalty from the firm to the manager in the event of permanent separation performs very poorly in creating incentives for the manager to realize firm-specific investments: such a contract induces a zero level of the manager's firm-specific ("internal") investment and it strongly motivates the manager to invest outside the employment relationship.

Finally, the contract featuring a large breach penalty from the firm to the manager is also compared with a contract in which the penalty is from the manager to the firm and, quite surprisingly, the latter proves to be superior in inducing firm-specific investments by the manager. In particular, when employment termination is never efficient, the contract with a large penalty against the manager leads to the first-best outcome, in which the manager invests only in the firm-specific activity. Conversely, when efficient separation cannot be ex-ante (that is, when the manager takes the decision

\footnotetext{
${ }^{2}$ For example, as reported in Almazan And Suarez [2003, p. 539], the 1995 Proxy statement of Apple Computer provides the following reason for adopting a golden parachute contractual arrangement: "to reinforce and encourage the continued attention and dedication of members of Apple's management in the atmosphere of uncertainty that might arise in the context of a change in control ...". Clearly, managers' attention and dedication represent particular forms of firm-specific investments.
} 
about investments) excluded, the manager decides to invest (efficiently) both inside and outside the employment relationship. Hence, even in such a case, the level of firm-specific investment chosen by the manager is higher than with the contract featuring a penalty against the firm.

To understand the intuition behind the main results summarized above, consider first the case of a contract establishing a breach penalty from the firm to the manager and suppose that in the ensuing wage negotiation (after the manager's investment decision) the surplus from employment is divided between parties with their external market opportunities acting as respective outside options. Outside options, as opposed to threat points, act as a lower bound to a party's payoff in bargaining, but otherwise they do not affect the final outcome (e.g. Osborne And Rubinstein [1990], Muthoo [1999]). ${ }^{3}$ In such a context, increasing the breach penalty against the firm increases the probability that the manager's outside option is binding. Indeed, the penalty could be set large enough to ensure that the manager's outside option is binding with probability one. In this case, in equilibrium, the manager's payoff (or wage) becomes equal to his/her outside option, which does not depend on the internal investment (because it is firmspecific). As a result, the manager has no incentive to invest in firm-specific activities. By contrast, the manager's outside option increases at the margin with his/her external investment and this provides strong incentives for the manager to make such kinds of investment.

Consider now the (symmetric) case of a contract in which the manager has to pay the firm a breach penalty and suppose that the penalty is set large enough to ensure that the firm's outside option is always binding. In such a case, the manager's payoff from negotiation is given by the joint-total-surplus less the firm's outside option. Thus, when employment is efficient, the managers can capture, through wage bargaining, the full marginal return of the internal investment and this creates full incentives for them to invest inside the firm (and no incentives for external investment).

The present paper is related to several contributions in the literature. First, it relates to an extensive literature, going back to Grout [1984] and Williamson [1985], which has analyzed efficiency of investments and the hold-up problem when contracts are incomplete (see MALCOMSON [1997] for a survey of employment contracts). In particular, several articles show how simple contracts, in which breach penalties play a crucial role, can induce efficient investments. Most notably, HART AND MoORE [1988] and MACLEOD AND MALCOMSOn [1993] highlight the role of breach penalties, unconditional on which a party initiates separation, in ensuring efficient pure self-investments and pure cooperative investments ${ }^{4}$ when ex-post (re)negotiation is possible, while FELLA [2005] analyzes the role of conditional breach penalties in motivating firms to invest in

\footnotetext{
${ }^{3}$ Several good reasons to adopt the outside option principle for the labor market are pointed out in MALCOMSON [1997, p. 1928]. Results are quite different if alternative market opportunities act as threat points (this is analyzed in the extension/discussion section).

${ }^{4} \mathrm{~A}$ pure self-investment generates direct benefits only for the investor, while a pure cooperative investment produces no direct benefits for the investor, but only for the counterpart (see Che and Hausch [1999]).
} 
workers' general training, which is a hybrid form of cooperative investment. This paper partially adopts MACLEOD AND MALCOMSON's [1993] framework to compare the manager's incentives to invest inside the employment relationship (which represent cooperative investments since they directly increase only the firm's revenue) with those to invest outside (which represent pure self-investments), when the former and the latter interact via wage bargaining. In a different framework for contract ex-post renegotiation, Edlin And Reichelstein [1996] and Che And Chung [1999] study alternative legal remedies for the breach of contracts in the presence of specific self-investments and cooperative investments, respectively, while SPIER AND WHINSTON [1995] analyze the role of stipulated damage provisions in protecting specific investments and (in)efficiently excluding competitors. However, all the above articles do not consider interaction between different types of investments. Investments interaction is analyzed in SEGAL AND Whinston [2000], CAi [2003] and Kessler And LüLfEsmann [2006] but with relation to different issues than that studied in this paper. ${ }^{5}$

Second, the paper deals with the corporate governance literature that aims at explaining the presence in managerial contracts of large severance payments and golden parachutes, which have generated contentious debate among scholars and practitioners (see Lefanowicz et al. [2000] for a survey). ${ }^{6}$ On the "proponent" side (sometimes also labeled as the "stockholder-interest hypothesis"), they are considered important tools for easing the alignment of managers' and shareholders' goals. By contrast, on the "opposing" side (also labeled as the "management-entrenchment hypothesis"), they are considered a typical example of the managers' rent-seeking condoned by the docile boards of directors and a device that would entrench a management team. In this perspective, the paper's main contribution is to show that one of the strongest arguments in support of the stockholder-interest hypothesis (i.e. encouraging managers' firm-specific skills formation) appears to be largely undeserved.

The paper is organized as follows. Section 2 introduces the model and analyzes the bargaining process that is central to final results. Section 3 presents some preliminary analysis. Section 4 contains the paper's main results, and especially analyzes the manager's ex-ante optimal investments choice under different contractual arrangements. Section 5 provides some extensions and a discussion of the main results. Section 6 concludes. More technical proofs are relegated to the Appendix.

\footnotetext{
${ }^{5}$ In particular, Segal And Whinston [2000] and CaI [2003] study, respectively, the effects of exclusive trade contracts and the optimality of joint asset ownership in an environment with (technological or cost) complementarity/substitutability between internal and external investments, while KESSLER AND LÜLFESMANN [2006] analyze complementarity between employersponsored general and specific training.

${ }^{6}$ Further references are provided in the discussion section.
} 


\section{Basic framework}

\subsection{Timing and investments}

The basic framework of this paper is partially modeled along the lines of MACLEOD And Malcomson [1993]. There are two risk-neutral parties: a manager and a firm (or a board of directors). Time is divided into the following phases and, for simplicity, no discounting is assumed.

At $t=0$ parties sign a contract that establishes a party has to pay the counterpart a breach penalty $p^{j}$ in the event of permanent separation, with $j=f$ if the penalty is against the firm and $j=m$ if the penalty is against the manager. ${ }^{7}$

At $t=1$ the manager makes an investments decision, which is not ex-ante contractible (because, for example, investments are not verifiable by a court). He/she may choose to make two different kinds of investments: an "internal" investment $i \geq 0$, which increases the manager's productivity inside the firm, and an "external" investment $e \geq 0$, which increases the manager's alternative market opportunities. The investment's monetary costs to the manager are given by $i$ and $e$, respectively.

At $t=2$ a random parameter $\theta$ is realized and it is assumed to be distributed according to a continuously differentiable distribution function $F(\theta)$ over a bounded support $[\underline{\theta}, \bar{\theta}]$. The random parameter may be interpreted as shocks affecting market conditions that influence the manager-firm transaction value besides their alternative market opportunities. It may also be related to the possibility that a change in the firm's control or ownership occurs at $t=2$.

Finally, at $t=3$, after the investments and the random shock are observed by both parties, the latter negotiate over a wage and, if an agreement is reached, an employment transaction is carried out, that is the firm's revenue is realized and the wage payment is made (obviously, if the firm has been taken over at $t=2$, contract negotiation occurs, at $t=3$, between the manager and a new board of directors). However, during the bargaining process, both parties are also free to terminate the employment relationship, i.e. the manager may decide to quit and the firm may decide to lay the manager off and to hire another one. In this case, however, a party must pay the counterpart the breach penalty according to the initial contract.

Let $\sigma=(i, e, \theta) \in \Sigma$ be the state of the world in $t=3$. Thus, for all $\sigma \in \Sigma$, the firm's output and revenue (price is normalized to one) is given by $y=y(i, \theta)$, while alternative market opportunities for the manager and the firm are denoted with $\widetilde{w}=\widetilde{w}(e, \theta)$ and $\tilde{\pi}=\tilde{\pi}(\theta)$, respectively. Note that, since the manager's alternative market opportunities do not depend on $i$, the latter is a firm-specific investment in Becker's sense. Moreover,

\footnotetext{
${ }^{7}$ Two aspects deserve to be recalled in relation to the initial contract. First, as in HART AND Moore [1988] and MacLeOd AND Malcomson [1993], the penalty is unconditional on which party initiates separation (this point is discussed in detail in Section 5.3). Secondly, the initial contract may also specify an initial wage (see MACLEOD AND MALCOMSON [1993]). It is assumed, however, that this wage is sufficiently low not to play any role in the employment/bargaining phase at $t=3$. This assumption permits to simplify the analysis that follows without substantially affecting the main results.
} 
since $i$ increases the firm's output but it does not affect the manager's alternative market opportunities, it is also a pure "cooperative" investment. Firm-specific skills formation by the manager (such as those concerning the special features of the firm's product, location or customers) represents the most typical example of this type of investment. However, also efforts to build a management team inside the firm, to develop a certain corporate culture or to establish links with costumers and other firms based on the manager's personal contacts may all represent other possible examples. Conversely, $e$ has no value inside the current employment relationship but only increases the manager's alternative market opportunities. ${ }^{8}$ For example, the manager may want to exert efforts in searching for alternative employment opportunities or to make investments tailored to the needs of potential alternative employers. Although such searching or investments add no value to the trade between the manager and the incumbent firm, they can play an important role in their relationship since they may enhance the manager's bargaining position against the firm.

The following assumptions are introduced:

Assumption 1 For all $\sigma \in \Sigma$, the functions $y(\cdot)$ and $\widetilde{w}(\cdot)$ are continuously differentiable, strictly increasing and strictly concave in $i$ and e, respectively. Furthermore, $y(\cdot)$ and $\widetilde{w}(\cdot)$ satisfy the Inada conditions and $\lim _{i \rightarrow \infty} y_{i}(\cdot) \rightarrow 0, \lim _{e \rightarrow \infty} \widetilde{w}_{e}(\cdot) \rightarrow 0$.

Assumption 2 For all $\sigma \in \Sigma, y(\cdot)>\widetilde{w}(\cdot)+\widetilde{\pi}(\cdot)$.

While Assumption 1 defines a set of standard technical conditions ensuring also that it is always socially optimal to have a strictly positive amount of at least one type of investment, Assumption 2 implies that it is always beneficial for parties to trade with each other. ${ }^{9}$ Since the state $\sigma$ is known to both parties at $t=3$ and, consequently, the bargaining process takes place under fully symmetric information, Assumption 2 also implies that parties will always reach an agreement and the employment relationship will continue over $t=3$. However, even if external market opportunities are never exercised, they may produce important effects on bargaining.

\subsection{Bargaining}

The bargaining process at $t=3$ is crucial in the model. In the subsequent analysis it is assumed that negotiation can be formalized by a bargaining solution which ensures efficiency and is characterized by the outside option principle.

Let $p=p^{f}$ be the breach penalty when the contract establishes that it is against the firm and with $p=-p^{m}$ when it is against the manager. Then the highest payoff (wage) the manager can obtain from bargaining is $\bar{w}(i, \theta, p)=y(i, \theta)-\widetilde{\pi}(\theta)+p$, as the firm can secure its reservation payoff $\tilde{\pi}(\theta)-p$ by firing the manager, while the lowest payoff the manager can obtain is $\underline{w}(e, \theta, p)=\widetilde{w}(e, \theta)+p$, the payoff to quitting

\footnotetext{
${ }^{8} \mathrm{~A}$ situation, in which the internal investment is purely cooperative and the external investment is purely "selfish", may represent an extreme case. The results that follow, referring to this case, need to be properly interpreted so as to include more general cases as well.

${ }^{9}$ Assumption 2 is relaxed in Section 5.1.
} 
unilaterally. Under Assumption 2, we have $\bar{w}(i, \theta, p)>\underline{w}(e, \theta, p)$ and there is always a range $[\underline{w}(e, \theta, p), \bar{w}(i, \theta, p)]$ of feasible agreements; ex-post bargaining determines where an equilibrium agreement lies within this range.

According to the bargaining solution specified above, and under Assumption 2, we can state now the following Result 1, which also defines the manager's ex-post payoff (since now, in order to streamline my exposition, the dependence of payoff on the state is omitted whenever unnecessary):

RESULT 1 (outside option principle) Let $\beta \in(0,1)$ be a measure of the relative bargaining power of the manager. Then, for all $\sigma \in \Sigma$ and for any breach penalty $p$ agreed at $t=0$, the equilibrium ex-post payoffs $w^{*}$ for the manager and $\pi^{*}$ for the firm, when employment continuation is efficient, are unique and satisfy $w^{*}+\pi^{*}=y$, where

$$
w^{*}(\sigma, p)= \begin{cases}\beta y & \text { if } \underline{w} \leq \beta y \leq \bar{w} \\ \underline{w} & \text { if } \beta y<\underline{w} \\ \bar{w} & \text { if } \beta y>\bar{w}\end{cases}
$$

According to (1) parties share the surplus from employment according to their relative bargaining power with their alternative market alternatives (outside options) that constitute a lower bound on each party's payoff but otherwise they do not affect the bargaining outcome. This result may be consistent with several extensive-form bargaining games in the context of labor market (e.g. Shaked And Sutton [1984], MacLeod AND MALCOMSON [1995]). ${ }^{10}$

\section{Preliminary analysis}

To define efficient levels of investments at $t=1$, let $v(\sigma)=\max \{y, \widetilde{w}+\widetilde{\pi}\}$ be the potential surplus accruing at $t=3$. Thus, the maximum ex-ante potential surplus from choosing efficient levels of investments is given by

$$
v^{*}=\max _{i \geq 0, e \geq 0}\{E[v(\sigma)]-i-e\}
$$

where $E[v(\sigma)]=\int_{\theta \in[\underline{\theta}, \bar{\theta}]} v(\sigma) d F(\theta)$.

Assumption 1 ensures that the solutions to (2) are unique and strictly positive. Furthermore, under Assumption 2, $v=y$ and the first-best solution is for the manager

\footnotetext{
${ }^{10}$ ShAKED AND SUTTON [1984] study a game, based on the alternating-offers bargaining game of Rubinstein, which unique subgame perfect equilibrium coincides in the limit, as discounting is negligible, with Result 1 (with $\beta=1 / 2$ ). MacLeOd And Malcomson [1995] use the variant of the Rubinstein game proposed by Binmore [1987] and develop a model of contract (re)negotiation in which trade occurs over time rather than at a single date. If a sufficiently low wage is established in the initial contract, the unique subgame perfect equilibrium in their model, when the time interval between offers vanishes, again coincides with Result 1.
} 
and the firm to trade. Thus the first-best (or ex-ante efficient) investment levels are, respectively, $i=i^{*}$ and $e=0$, where $i^{*}$ satisfies the following first-order condition:

$$
\int_{\theta \in[\underline{\theta}, \bar{\theta}]} y_{i}\left(i^{*}, \theta\right) d F(\theta)=1 .
$$

Because of contract incompleteness (e.g. it is difficult or impossible to prevent people from searching for outside opportunities by contractual means) ${ }^{11}$, a contract for the manager specifying $\left\{i^{*}, 0\right\}$ should be, in general, non-enforceable. This can generate inefficient outcomes. As an important benchmark case, consider the situation in which parties have not signed any contract at $t=0$ and there are no outside options, ${ }^{12}$ i.e. $p=\widetilde{w}=\widetilde{\pi}=0$. In this case, according to (1), parties are going to share the ex-post surplus according to their relative bargaining power (that is, the manager takes $\beta y$ and the firm obtains $(1-\beta) y)$. Thus at $t=1$, in equilibrium, clearly $e$ should be zero, while the investment level $i$ chosen by the manager (labeled with $\widehat{i}$ ) is defined by the following first-order condition:

$$
\left.\beta \int_{\theta \in[\underline{\theta}, \bar{\theta}]} y_{i} \widehat{(i,}, \theta\right) d F(\theta)=1 .
$$

Comparing (4) with (3) shows that the equilibrium investment $\widehat{i}$ will be lower than in the first-best solution $\left(\widehat{i}<i^{*}\right)$. This is the classic Williamson's hold-up result $(\text { WiLliamSON [1985]) })^{13}$; taking into account that under ex-post surplus-sharing he/she will be able to take only a fraction $\beta$ of his/her investment's (marginal) return, the manager will rationally decide ex-ante to under-invest.

\section{Investments decision}

In order to investigate the manager's ex-ante decision about how much to invest in $i$ and $e$, define, for future reference, the following possible states at $t=3$ for given levels of investments $i$ and $e$, and a given breach penalty $p$ :

$$
\begin{aligned}
& \widehat{s}(i, e, p)=\{\theta \in[\underline{\theta}, \bar{\theta}]: \underline{w} \leq \beta y \leq \bar{w}\} \\
& \underline{s}(i, e, p)=\{\theta \in[\underline{\theta}, \bar{\theta}]: \beta y<\underline{w}\} \\
& \bar{s}(i, e, p)=\{\theta \in[\underline{\theta}, \bar{\theta}]: \beta y>\bar{w}\}
\end{aligned}
$$

where $(\widehat{s} \cup \underline{s} \cup \bar{s})=[\underline{\theta}, \bar{\theta}]$.

\footnotetext{
${ }^{11} \mathrm{But}$, on this point, see also the discussion on noncompetition clauses in Section 5.4. Instead, a somewhat different situation is represented by "exclusive contracts", that is contracts that prohibit one party from dealing with other agents outside the relationship (see SEGAL AND Whinston [2000] for the effects of exclusive contracts on non-contractible investments).

${ }^{12}$ Alternatively, we can assume that outside options never bind.

${ }^{13}$ See also Grout [1984] for the first formalization of this result.
} 
Expression (5) defines all possible (sets of) states that can occur at $t=3$. In particular, under $\widehat{s}$ the surplus-sharing outcome applies in equilibrium, while $\underline{s}$ and $\bar{s}$ define the states in which the manager's and the firm's outside options are binding, respectively. Thus, according to (5), we can define, in its most general form, the manager's (ex-ante) expected payoff at $t=1, E[w(\sigma, p)]-i-e$, as follows:

$$
\int_{\theta \in \widehat{s}} \beta[y(i, \theta)] d F(\theta)+\int_{\theta \in \underline{s}} \underline{w}(e, \theta, p) d F(\theta)+\int_{\theta \in \bar{s}} \bar{w}(i, \theta, p) d F(\theta)-i-e
$$

and the marginal (expected) returns to invest in $i$ and $e$ are, respectively:

$$
\beta \int_{\theta \in \widehat{s}} y_{i}(i, \theta) d F(\theta)+\int_{\theta \in \bar{s}} y_{i}(i, \theta) d F(\theta)
$$

and

$$
\int_{\theta \in \underline{s}} \widetilde{w}_{e}(e, \theta) d F(\theta)
$$

Obviously, the manager invests in $i$ and $e$ so as to equalize their marginal returns, defined respectively by (7) and (8), to their marginal costs (subject to the non-negativity constraints $i \geq 0$ and $e \geq 0$ ). Thus, in equilibrium, the manager's investment levels satisfy the following conditions (in which $\bar{i}$ and $\bar{e}$ define the manager's equilibrium investments):

$$
\begin{gathered}
\beta \int_{\theta \in \widehat{s}} y_{i}(\bar{i}, \theta) d F(\theta)+\int_{\theta \in \bar{s}} y_{i}(\bar{i}, \theta) d F(\theta) \leq 1,=1 \text { for } \bar{i}>0 \\
\int_{\theta \in \underline{s}} \widetilde{w}_{e}(\bar{e}, \theta) d F(\theta) \leq 1,=1 \text { for } \bar{e}>0 .
\end{gathered}
$$

Before turning to analyze in detail the effects of large breach penalties on the manager's investments decision, it is worth investigating, from (6), how internal and external investments interact:

RESULT 2 The manager's expected payoff function (6) is supermodular in $(i,-e)$. Therefore, internal and external investments are substitutes, i.e. equilibrium internal (external) investment by the manager is non-increasing in the level of external (internal) investment. 
Proof See the Appendix.

Intuitively, by investing in $e$, the manager receives higher external wage offers and his/her outside option will therefore be binding more frequently, ceteris paribus. However, since the manager's marginal return of investing in $i$ is zero when his/her outside option is binding, investing in $e$ reduces his/her incentives to invest in $i$. Similarly, investing in $i$ increases the probability that a bargaining outcome (namely, surplus-sharing), in which the manager's marginal return to invest in $e$ is zero, occurs and this reduces his/her incentives to invest in $e$.

\subsection{Investments with large breach penalties against the firm}

Contractually stipulated breach penalties may strongly influence the manager's investment decisions since, when sufficiently large, they affect bargaining outcome by excluding some possible states, defined in (5), from happening at $t=3 .{ }^{14}$ In order to investigate this issue, consider first the most widely discussed case (see the Introduction Section) in which the penalty $\left(p^{f}\right)$ is from the firm to the manager. In particular, in this section it will be shown that: a) the manager's internal and external investments are non-increasing and non-decreasing in $p^{f}$, respectively; and b) there could be a penalty against the firm large enough, according to which the manager does invest only in $e$. The following result, whose proof is provided in the Appendix, formally states the point a):

RESULT 3 Equilibrium internal and external investments by the manager are non-increasing and non-decreasing in $p^{f}$, respectively.

Proof See the Appendix.

The intuition behind Result 3 is simple. Since larger $p^{f}$ 's values increase the probability that the manager's outside option is binding, they motivate the manager to invest outside the incumbent employment relationship. By contrast, they perform very poorly in inducing incentives for the manager to realize firm-specific investments.

Consider now a large enough breach penalty $p^{f}=P^{f}$ that, for any given $i$ and $e$, satisfies the following condition:

$$
P^{f}>\beta y-\widetilde{w}
$$

for any $\theta \in[\underline{\theta}, \bar{\theta}]$.

Given the breach penalty $P^{f}$, and labeling with $\bar{i}^{P^{f}}$ and $\bar{e}^{P^{f}}$ the manager's equilibrium investments under that contract, we can state the following result, whose proof is provided below:

\footnotetext{
${ }^{14}$ In a context with only self-investments, HART AND MOORE [1988] first analyze the role of breach penalties in affecting investment decision, by excluding ex-post negotiation outcomes from occurring.
} 
RESULT 4 Under a breach penalty $P^{f}$ agreed at $t=0$, the manager under-invests in $i$ and over-invests in e when employment continuation is always efficient.

Proof Under the breach penalty $P^{f}$ (that satisfies (11)), the manager's outside option is always binding. Thus, according to (1), the only bargaining outcome that arises in equilibrium implies a manager's expected payoff at $t=1$, given by:

$$
E\left[w\left(\sigma, P^{f}\right)\right]-i-e=\int_{\theta \in[\underline{\theta}, \bar{\theta}]}\left[\widetilde{w}(e, \theta)+P^{f}\right] d F(\theta)-i-e .
$$

According to (12), since the manager's marginal (expected) returns to invest in $i$ and $e$ are zero and $\int_{\theta \in[\underline{\theta}, \bar{\theta}]} \widetilde{w}_{e}(e, \theta) d F(\theta)$, respectively, in equilibrium the manager does not invest in $i\left(\bar{i}^{P^{f}}=0\right)$, while he/she does invest in $e$ such that $\int_{\theta \in[\underline{\theta}, \bar{\theta}]} \widetilde{w}_{e}\left(\bar{e}^{P^{f}}, \theta\right) d F(\theta)=1$, which implies $\bar{e}^{P^{f}}>0$.

Q.E.D.

Result 4 can be explained as follows: when the initial contract establishes a breach penalty from the firm to the manager large enough to ensure that the manager's outside option is always binding, the manager is sure to be able to recoup (by means of wage bargaining) the full marginal return of the investment that increases his/her alternative market opportunities. This is true even if, at the end, parties do not separate. By contrast, since under the penalty $P^{f}$ the manager does not recoup any of the investment $i$ 's marginal return, he/she does not invest in $i$ at all (note also that when condition (11) is satisfied, any further increase in the absolute value of the penalty has no effect on the manager's investments). Thus, under a contract that specifies $P^{f}$, the level of internal investment provided by the manager is lower even relative to the case, analyzed in Section 3, without outside options (in which $\widehat{i}>0$ ).

\subsection{Investments with large breach penalties against the manager}

This section is symmetric with respect to the previous one. In particular, the case of a breach penalty $\left(p^{m}\right)$ from the manager to the firm will be considered and it will be shown that, firstly, the manager's internal and external investments are non-decreasing and non-increasing in $p^{m}$, respectively, and, secondly, there could be a penalty against the manager large enough by which he/she invests only in $i$.

RESULT 5 Equilibrium internal and external investments by the manager are non-decreasing and non-increasing in $p^{m}$, respectively.

Proof See the Appendix.

Q.E.D.

Since increasing the breach penalty against the manager raises the probability that the firm's outside option is binding, Result 5 can be better understood, in a similar fashion as in Section 4.1, by analyzing the (extreme) case, in which the penalty is so 
large that the firm's outside option is always binding. For this goal, consider an initial contract, which establishes a breach penalty $p^{m}=P^{m}$ from the manager to the firm that, for any given $i$ and $e$, satisfies:

$$
P^{m}>(1-\beta) y-\tilde{\pi}
$$

for any $\theta \in[\underline{\theta}, \bar{\theta}]$.

Given the penalty $P^{m}$, and labeling with $\bar{i}^{P^{m}}$ and $\bar{e}^{P^{m}}$ the manager's equilibrium investments under that penalty, we can state the following result, whose proof is provided below:

RESULT 6 Under a breach penalty $P^{m}$ agreed at $t=0$, the manager invests efficiently when employment continuation is always efficient.

Proof Under the breach penalty $P^{m}$ (that satisfies (13)), the firm's outside option is always binding. Thus, according to (1), the only bargaining outcome that arises in equilibrium implies a manager's expected payoff at $t=1$, given by:

$$
E\left[w\left(\sigma, P^{m}\right)\right]-i-e=\int_{\theta \in[\underline{\theta}, \bar{\theta}]}\left[y(i, \theta)-\widetilde{\pi}(\theta)-P^{m}\right] d F(\theta)-i-e .
$$

According to (14), since the manager's (expected) marginal returns to invest in $i$ and $e$ are $\int_{\theta \in[\underline{\theta}, \bar{\theta}]} y_{i}(i, \theta) d F(\theta)$ and zero, respectively, in equilibrium the manager does not invest in $e\left(\bar{e}^{P^{m}}=0\right)$, while he/she does invest in $i$ such that $\int_{\theta \in[\underline{\theta}, \bar{\theta}]} y_{i}\left(\bar{i}^{P^{m}}, \theta\right) d F(\theta)=1$, which implies $\bar{i}^{m}=i^{*}$.

Q.E.D.

Results 5 and 6 suggest that breach penalties from the manager to the firm may increase the manager's incentives to invest in firm-specific (internal) activities and, if compared with results of Section 4.1, that penalties against the manager perform much better than those against the firm when employment continuation is always efficient. ${ }^{15}$ Hence, they provide a rationale for breach penalties from the manager to the firm. There could be, however, possible reasons that may discourage their presence in managerial contracts (at the same time, there are some substitutes that we observe in the real world). This will be discussed in Section 5.4.

\section{Some extensions and discussion}

\subsection{Possible efficient separation}

In the basic framework, efficient separation is ruled out by Assumption 2, which establishes that it is always efficient for parties to trade with each other. By contrast, if

\footnotetext{
${ }^{15}$ Note again that when condition (13) is satisfied, any further increase in the absolute value of the penalty against the manager has no effect on the manager's investments.
} 
that assumption is relaxed, two issues are worth addressing. First, whether separation decisions are made efficiently (given the existence of breach penalties). Secondly, how the manager modifies his/her investments decision when separation is a possible event, particularly with respect to the ex-ante efficient levels.

In relation to the first point, it is important to recall that, since penalties are pure monetary transfers between parties, under fully symmetric information over bargaining they cannot affect the final separation decision, which is always efficient. ${ }^{16}$ In particular, separation occurs whenever $y<\widetilde{w}+\widetilde{\pi}$. This is because, in such a case, we have that $\bar{w}=y-\tilde{\pi}+p<\underline{w}=\widetilde{w}+p$ (i.e. the highest payoff the firm is able to concede to the manager through bargaining is lower than the payoff the manager can attain by quitting unilaterally). Hence there is always one party that unilaterally prefers to terminate the employment relationship.

Turning to the second issue, it is important to define, in the first place, the social optimal (ex-ante efficient) investment levels when efficient separation is a possible event and, secondly, to analyze the performances of different contracts (penalties) with respect to those levels. Efficient levels of investments at $t=1$ maximize the ex-ante potential surplus $E[v(\sigma)]-i-e$, where now $E[v(\sigma)]=\int_{\theta: y \geq \widetilde{w}+\widetilde{\pi}} y(i, \theta) d F(\theta)+\int_{\theta: y<\widetilde{w}+\widetilde{\pi}}[\widetilde{w}(e, \theta)+$ $\tilde{\pi}(\theta)] d F(\theta)$. Thus first-best internal and external investments, when efficient separation is a possible event, are both strictly positive and must satisfy the following first-order conditions (subscript $E S$ is used in what follows to identify results for the case in which efficient separation is possible):

$$
\begin{gathered}
\int_{\theta: y \geq \widetilde{w}+\widetilde{\pi}} y_{i}\left(i_{E S}^{*}, \theta\right) d F(\theta)=1 \\
\int_{\theta: y<\widetilde{w}+\widetilde{\pi}} \widetilde{w}_{e}\left(e_{E S}^{*}, \theta\right) d F(\theta)=1 .
\end{gathered}
$$

The point now is to analyze how large breach penalties perform with respect to $i_{E S}^{*}$ and $e_{E S}^{*}$. Consider first the contract providing for a large breach penalty from the firm to the manager $\left(p^{f}=P^{f}\right)$. In relation to results of Section 4.1, introducing the possibility of ex-post separation does not produce any modification to the manager's decision about investments. This is because the manager's payoff at $t=3$ when parties separate is exactly the same as when they trade with each other under the contract providing for $P^{f}$ : whichever state of the world realizes at $t=3$, the manager obtains a payoff equals to $\widetilde{w}+P^{f}{ }^{17}$ This implies that, as in Section 4.1, the investment levels chosen in equilibrium by the manager are $\bar{i}_{E S}^{P^{f}}=0$ and $\bar{e}_{E S}^{P^{f}}=\bar{e}^{P^{f}}$, respectively. Furthermore, since $\bar{i}_{E S}^{P^{f}}<i_{E S}^{*}$ and $\bar{e}_{E S}^{P^{f}}>e_{E S}^{*}$, Result 4 (i.e. under a breach penalty $P^{f}$ the manager under-invests in

\footnotetext{
${ }^{16}$ This is a straightforward application of the Coase theorem.

${ }^{17}$ Obviously, $\widetilde{w}+P^{f}$ will be a wage payment by the firm, if employment continuation results ex-post efficient, or a payoff from an alternative market opportunity (plus the penalty from the firm), in the case of ex-post separation.
} 
$i$ and over-invests in $e$ when employment is always efficient) extends also to the case in which ex-post separation is a possible event.

Consider, instead, the case of a large penalty against the manager $\left(p^{m}=P^{m}\right)$. Now the manager must take into account that, if separation occurs, his/her payoff does not depend on the internal investment at all, but it increases only with the external investment. In comparison with the case in which employment continuation is always efficient, on the one hand, this decreases the manager's incentives to invest in firm-specific activities and, on the other, increases the manager's incentives to invest outside the employment relationship $\left(\bar{i}_{E S}^{P^{m}}<\bar{i}^{P^{m}}\right.$ and $\left.\bar{e}_{E S}^{P^{m}}>\bar{e}^{P^{f}}\right)$. However (and more importantly), under the breach penalty $P^{m}$, the manager can capture the full marginal return of the internal investment when the match survives (because in such a case his/her payoff is $\left.y-\widetilde{\pi}-P^{m}\right)$ and the full marginal return of the external investment when parties separate (since, in this case, his/her payoff is $\widetilde{w}-P^{m}$ ). This implies that, in equilibrium, the investment levels chosen by the manager satisfy conditions (15) and (16), respectively $\left(\bar{i}_{E S}^{P^{m}}=i_{E S}^{*}\right.$ and $\left.\bar{e}_{E S}^{P^{m}}=e_{E S}^{*}\right)$. Hence, also Result 6 (i.e. under a breach penalty $P^{m}$ the manager invests efficiently when employment is always efficient) extends to the case in which ex-post separation is possible.

\subsection{Alternative market opportunities acting as threat points}

In the previous analysis it was assumed that parties negotiate according to the outside option principle, in which alternative market opportunities serve as constraints on bargaining agreements. Even if there are several good reasons to adopt the outside option principle for the labor market (e.g. MALCOMSON [1997]), it is worth briefly analyzing (and concentrating only on the case in which employment continuation is always efficient) how results might change by adopting an alternative bargaining protocol. The most prominent alternative bargaining scenario to the outside option principle is represented by the Nash bargaining solution. The latter is appropriated in situations where bargainers receive their alternative market opportunities while continuing to bargain. That is, in our model, the manager takes another job and the firm hires another manager temporarily, during the negotiation, but with a less good match so that there are potential gains from continuing negotiation. In this case, when employment continuation is efficient, in equilibrium, parties obtain from negotiation, and according to their bargaining power, a share of the gains from trade over and above their respective alternative market opportunities (which hence operate as threat points). ${ }^{18}$

It is important to remark that in this different framework the role of breach penalties is very different. ${ }^{19}$ Namely, since the (equilibrium) payoffs' structure is unique and it does not depend on breach penalties, they do not affect investment decision, but only

\footnotetext{
${ }^{18}$ In a strategic framework, this applies in an alternating-offer bargaining game in which bargaining breaks down with a small probability whenever an offer is rejected and the two players get their alternative market opportunities in a bargaining breakdown. As BinMore et al. [1986] show, the unique subgame-perfect equilibrium of this game coincides with the Nash bargaining solution in the limit when the probability of bargaining breakdown goes to zero.

${ }^{19}$ Indeed, in this different scenario the breach penalty is not related to permanent separation
} 
produce distributional effects. This also implies that, in relation to the manager's choice about investments, it is not relevant which party the penalty is established upon. To formally show this statement, consider an initial contract with a large breach penalty against one party. Since, in equilibrium, parties share the surplus from employment according to the Nash bargaining solution, the manager's ex-post payoff is given by $\widetilde{w}+p+\beta(y-\widetilde{w}-\widetilde{\pi})$ (remind that $p=p^{f}$ if the penalty is against the firm and $p=-p^{m}$ if it is against the manager). As a consequence, whichever is the party upon which the penalty is established, conditions defining the manager's ex-ante optimal choice about investments (labeled with $\widetilde{i}$ and $\widetilde{e}$, respectively) are the following:

$$
\begin{gathered}
\left.\beta \int_{\theta \in[\underline{\theta}, \bar{\theta}]} y_{i} \widetilde{(i}, \theta\right) d F(\theta)=1 \\
(1-\beta) \int_{\theta \in[\underline{\theta}, \bar{\theta}]} \widetilde{w}_{e}(\widetilde{e}, \theta) d F(\theta)=1 .
\end{gathered}
$$

From (17) and (18) we can infer that: $0=\bar{i}^{p^{f}}<\widetilde{i}(=\widehat{i})<\bar{i}^{p^{m}}=i^{*}$ and $0=\bar{e}^{p^{m}}<$ $\widetilde{e}<\bar{e}^{p^{f}}$. Thus, the results we have with large penalties (against the firm or against the manager) and alternative market opportunities acting as threat points (further than efficient employment continuation) fall in between those related to the outside option principle. Moreover, the manager always under-invests in $i$ and over-invests in $e$.

\subsection{Unconditional vs. conditional penalties}

Previous analysis has emphasized the role of large privately stipulated breach penalties in affecting managers' investment decisions. This and the following sections discuss some relevant issues concerning breach penalties in managerial contracts.

First of all, it is worth defining the empirical relevance of the type of breach penalties studied in this paper (that is, penalties that are unconditional on which party initiates separation) and discussing in what way results would change with conditional penalties. In this regard, with reference to payments from the firm to the manager, it is important to point out that under a golden parachute contractual arrangement the manager can voluntarily quit the firm after a change in control and obtain the agreed-upon payment. For example, the 1982 Proxy Statement of Superior Oil (as reported in LAMBERT AND LARCKER [1985, p. 180]) describes their golden parachute contracts as providing “... for a lump sum termination compensation payment [...] to an officer in the event of his termination of employment for any cause, whether voluntary or involuntary (other than death, disability, willful misconduct or normal retirement), within one year of a change of control of the Company". Thus, golden parachutes represent unconditional payments in all respects.

but it is more correctly a payment made if neither trades at all. 
Furthermore, in some circumstances, also breach penalties in the form of severance or redundancy pay may be largely independent of which party terminates the employment contract. For instance, employment agreements often establish that an employee may be able to claim severance pay after also voluntarily quitting if this event is related to something out of his/her control (e.g. the firm radically changed the employee's assignment). ${ }^{20}$

Conversely, penalties against the manager for the event of permanent separation are actually rare. Importantly, this holds not only for the case in which the firm fires the manager (unconditional penalty) but also when it is the manager who voluntarily terminates the employment relationship (possible reasons for this are discussed in Section $5.4)$.

Conditional penalties are studied in FELLA [2005] in relation to their role in motivating firms to invest in workers' general training. In a framework similar to that of this paper, Fella shows that conditional penalties can produce two main results: a) they reduce the probability that parties' outside options are binding (and, as a consequence, increase the probability for the surplus-sharing outcome to apply) when employment is ex-post efficient; and b) they create scope for bargaining and allow parties to capture a share of the joint surplus even in case of separation. Intuitively, results a) and b) can be explained as follows. Conditional penalties reduce both parties' outside options because any one party that decides to unilaterally terminate the match and take his/her outside option must now pay the penalty. Furthermore, it could happen that separation proves efficient, but no party has an incentive to unilaterally terminate the match (because he/she has to pay the penalty). Yet, since employment termination yields a strictly positive joint surplus, it is optimal for the parties to agree to renegotiate the contracted termination payments in order to separate, thereby sharing the surplus according to their relative bargaining power. In particular, it is shown that parties may agree in the initial contract on conditional separation payments sufficiently large that, independently of outside opportunities, parties share the surplus from employment continuation or separation, according to the state of the world that ensues.

Applying FELLA's [2005] results to this framework, and defining with $P_{c}^{f}$ and $P_{c}^{m}$ the conditional penalties against the firm and the manager, respectively, such penalties (which may or may not be equal) must be set large enough that, for any given $i$ and $e$, the following condition is satisfied:

$$
\widetilde{w}-P_{c}^{m} \leq \beta v \leq v-\widetilde{\pi}+P_{c}^{f}
$$

for any $\theta \in[\underline{\theta}, \bar{\theta}]$.

\footnotetext{
${ }^{20}$ More in general, enforcement problems and costs may often make penalties conditional on which party actually produces separation ineffective. An example can be represented by the cases brought for "constructive discharge", in which, even though the employee quits, the employer might have, in effect, terminated him/her, by making working conditions such that it is virtually impossible for the employee to stay. A symmetric situation may apply when a worker wanting to quit behaves badly enough to induce dismissal (see MALCOMSON [1997] for further discussion and legal details).
} 
When conditional penalties are sufficiently large to satisfy condition (19) and employment continuation is ex-post efficient $(\theta: v=y)$, we have $\widetilde{w}-P_{c}^{m} \leq \beta y \leq y-\widetilde{\pi}+P_{c}^{f}$ and, according to (1), surplus-sharing always applies in equilibrium. Instead, when separation is ex-post efficient $(\theta: v=\widetilde{w}+\widetilde{\pi})$, we have $\widetilde{w}-P_{c}^{m} \leq \beta(\widetilde{w}+\widetilde{\pi}) \leq \widetilde{w}+P_{c}^{f}$. Since this simultaneously satisfies $\beta(\widetilde{w}+\widetilde{\pi}) \geq \widetilde{w}-P_{c}^{m}$ and $(1-\beta)(\widetilde{w}+\widetilde{\pi}) \geq \widetilde{\pi}-P_{c}^{f}$, both parties consensually prefer to renegotiate the initial contract (penalties) in order to terminate the employment relationship and share the joint surplus from separation (that is, payoffs parties receive from separation are $\beta(\widetilde{w}+\widetilde{\pi})$, for the manager, and $(1-\beta)(\widetilde{w}+\widetilde{\pi})$, for the firm).

According to the above results, it is important to further clarify the role that conditional penalties can play in the context studied in this paper. ${ }^{21}$ In this regard, since a large breach penalty against the manager, such as $P^{m}$, can implement the first-best (as shown in Sections 4.2 and 5.1), conditional penalties cannot improve things. However, it is important to analyze if they make things worse. For this goal, we must define, in the first place, the equilibrium investment levels with conditional penalties.

As explained above, with penalties $P_{c}^{f}$ and $P_{c}^{m}$ the manager ex-post payoff is $\beta y$ when the match survives and $\beta(\widetilde{w}+\widetilde{\pi})$ when parties separate. Hence, the investment levels chosen in equilibrium by the manager are defined by the following first-order conditions (where $\bar{i}_{E S}^{P_{c}}$ and $\bar{i}_{E S}^{P_{c}}$ stands for the equilibrium internal and external investment, respectively, with conditional penalties and when separation is sometimes efficient):

$$
\begin{gathered}
\beta \int_{\theta: y \geq \widetilde{w}+\widetilde{\pi}} y_{i}\left(\bar{i}_{E S}^{P_{c}}\right) d F(\theta)=1 \\
\beta \int_{\theta: y<\widetilde{w}+\widetilde{\pi}} \widetilde{w}_{e}\left(\bar{e}_{E S}^{P_{c}}\right) d F(\theta)=1 .
\end{gathered}
$$

Comparing (20) with (15) and (21) with (16), we have that $\bar{i}_{E S}^{P_{c}}<i_{E S}^{*}$ and $\bar{e}_{E S}^{P_{c}}<e_{E S}^{*}$. That is, with (large) conditional penalties the manager under-invests both in $i$ and $e$ when separation is sometimes efficient. Furthermore, since a large unconditional penalty against the manager implements first-best, this also implies that conditional penalties make things worse than the former. The reason for this can be explained as follows. Under a contract providing for $P^{m}$ (as we have seen in Section 5.1), the manager is able to capture the full marginal return of the internal investment when the match survives and the full marginal return of the external investment when parties separate. By contrast, with conditional penalties he/she can reap only a fraction $\beta$ of those marginal returns, thereby he/she under-invests, with respect to social optimum, for both types of investment.

\footnotetext{
${ }^{21}$ In relation to workers' general training by firms, FeLLA [2005] shows that conditional breach penalties (satisfying a condition analogous to (19)) prove to be the (second-)best solution. In particular, since training is vested in the worker on separation, what is crucial is the possibility for the firm to capture, even in this case, a positive share of its return on investment from agreeing to separate.
} 
Note, instead, that if we compare (with respect to first-best outcomes) results with conditional penalties against those with a large unconditional breach penalty against the firm, we have: $0=\bar{i}_{E S}^{P_{f}}<\bar{i}_{E S}^{P_{c}}<i_{E S}^{*}$ and $\bar{e}_{E S}^{P_{c}}<e_{E S}^{*}<\bar{e}_{E S}^{P_{f}}$. Hence, from an efficiency viewpoint, a large unconditional penalty against the firm represents the worst case scenario in relation to internal investments. Instead, with reference to external investments, results are not comparable at once, since the manager, from one side, under-invests with conditional penalties and, from the other side, over-invests with an unconditional penalty against the firm.

\subsection{Why are breach penalties against managers not so common (and are those against firms more common)?}

Previous results seem to suggest that, in motivating managers to realize firm-specific investments (e.g. skills formation), contracts in which the manager must pay the firm large penalties if parties permanently separate should be superior to those in which the firm must pay the manager the penalty. An objection that can be leveled at these results is that, while breach penalties against managers for the event of permanent separation are rare, breach penalties against firms are more common in reality. In this section, possible reasons for both these occurrences are advanced. Moreover, it is also argued that some other contractual arrangements, which are more frequently observed in managerial contracts, can operate, at least partly, as substitutes of breach penalties against managers.

As pointed out by MALCOMSON [1997], a first general issue with breach penalties is that the lowest penalty that can satisfy conditions such as (13) (but also (11)) above, and thus creating managers' incentives to invest, can be very large, but courts will not often enforce privately stipulated breach penalties in excess of the actual loss parties incur from contract termination. Moreover, even when they are legally enforceable, contractually stipulated breach penalties against managers can be discouraged by the presence of managers' liquidity constraints, which may render such payments problematic. $^{22}$ There are, however, some other contractual arrangements, more often observed in managerial contracts, which may operate as substitutes of breach penalties against managers. For instance, "post-employment restraint agreements" (or noncompetition clauses), which have become increasingly popular in recent decades and have been the subject of considerable controversy and debate (e.g. CALLAHAN [1985]), may operate in this direction. Under such provisions, a manager may agree not to work for a competitor of the firm or to establish a competing business for a defined duration after contract is terminated, or may agree to limit her disclosure of specified information in the event he/she continues to work in the same industry. Since all these agreements clearly reduce

\footnotetext{
${ }^{22} \mathrm{By}$ avoiding the problems of contracts that require managers to make payments to firms, alternative mechanisms to induce managers' firm-specific investments (and to reduce managers' temptation to invest efforts and resources "outside" the incumbent employment relationship), such as performance-related-pay and "up-or-out" contracts, can prove easier to implement. See, e.g., GibBons [1998] for a survey and detailed references on performance-related-pay and up-or-out contracts.
} 
managers' alternative market opportunities and, therefore, make their outside options binding less frequently, they reduce managers' incentives to invest outside and, consequently, increase those to invest inside the employment relationship (since the former and the latter are substitutes via bargaining). In addition, since removing these clauses by the payment of a penalty against the manager has also found some judicial support (e.g. LONG [2005]), they can also replicate more closely the type of breach penalties discussed in this paper. Finally, "golden handcuffs" (i.e. financial incentives and benefits, such as pensions, given by firms to existing employees in the hope that they will decide to stay with them) and, more generally, deferred compensation schemes, by increasing the manager's opportunity-cost to leave the firm, can produce the same effects than noncompete clauses. ${ }^{23}$

With reference to clauses that establish the firm has to pay the manager the breach penalty, observed in many managerial contracts, it is important to remark, firstly, that the "management-entrenchment" vs. "stockholder-interest" debate is still open and the former remains a strong hypothesis. Indeed, while the first empirical research (e.g. LAMBERT AND LARCKER [1985]) seemed to support the stockholder-interest hypothesis, more recent empirical studies (e.g. Mogavero And Toyne [1995]) have found no positive reaction of stock prices to golden parachutes. ${ }^{24}$ In addition, there could be possible reasons, other than encouraging managers to invest in firm-specific activities, which have been analyzed by the literature according to the perspective of aligning (incumbent) managers' and shareholders' goals. In particular, severance pay and golden parachutes may function as a payment to top executives not to resist shareholders' value-enhancing takeovers (Jensen And Ruback [1983], Harris [1990]). Moreover, they could operate as a mechanism current shareholders and managers use to extract rents from a future management team (Chung [1992], Spier And Whinston [1995]) or to partially shift the managerial compensation burden to the future buyer of the firm (CHOI [2004]).

\section{Conclusion}

In this paper, managers' incentives to invest in firms' specific skills or activities ("internal" investments) were compared with those to realize activities to increase their alternative market opportunities ("external" investments), when managerial contract establishes that one party has to pay the counterpart a large breach penalty in the event of employment termination. In this context, it is shown that: first, even if no technology or cost interaction exists between internal and external investments, they

\footnotetext{
${ }^{23}$ In Kessler AND LÜLFESMAnN [2006, p. 920] the argument is advanced that also the use of vested stock as a part of a manager's remuneration package may serve as a substitute for explicit breach penalties against the manager if those are difficult to enforce.

${ }^{24}$ It is important also to note, however, that, from a theoretical viewpoint, the two hypotheses are not necessarily inconsistent with one another. For instance, in AlmazAN AND SUAREZ [2003] it is shown that corporate governance structures that involve some degree of entrenchment can be optimal in terms of maximizing shareholders' value.
} 
are "incentive" substitutes from the manager's viewpoint. That is, increasing the level of one type of investment reduces (via wage bargaining) the incentives to realize the other type. Secondly, conversely to what is asserted by a strand of corporate governance literature (i.e. large breach penalties from firms to managers can motivate the latter to realize firm-specific investments), large breach penalties against firms reduce managers' incentives to invest inside (and raise those to invest outside) the incumbent employment relationship. Finally, large breach penalties against managers can perform better, than those against firms, in enhancing the realization of firm-specific skills or activities by the manager. In this regard, it was also discussed that while there could be different reasons that discourage the presence of those penalties in managerial contracts, some other contractual arrangements, more often observed in the real world, may operate as substitutes.

\section{Appendix}

\section{A.1 Proof of Result 2}

Result 2 states that the manager's expected payoff function (6) is supermodular in $(i,-e)$.

Proof In Euclidean applications, supermodularity means that increasing any subset of the decision variables raises the incremental returns associated with increases in the others (e.g. Milgrom And Shannon [1994, p. 164]). Thus, $E[w(\cdot)]$ is supermodular in $(i,-e)$ if and only if: a) $\partial E\left[w\left(i, e^{\prime}, \cdot\right)\right] / \partial i \geq \partial E[w(i, e, \cdot)] / \partial i$ for all $i$ and $-e^{\prime}>-e$ or, equivalently, $e^{\prime}<e$; and b) $\partial E\left[w\left(i^{\prime}, e, \cdot\right)\right] / \partial e \geq \partial E[w(i, e, \cdot)] / \partial e$ for all $e$ and $-i^{\prime}>-i$ or, equivalently, $i^{\prime}<i$.

Without loss of generality, consider the case in which $p=0$. Furthermore, consider that the generic set $s^{\prime}=s\left(x^{\prime}, z\right)$, with $x, z \in\{i, e\}$ and $x \neq z$. Using (7), condition related to point a) above is equivalent to:

$$
\begin{gathered}
e^{\prime}<e \Rightarrow \beta \int_{\theta \in \widehat{s}^{\prime}} y_{i}(i, \theta) d F(\theta)+\int_{\theta \in \bar{s}^{\prime}} y_{i}(i, \theta) d F(\theta) \geq \\
\beta \int_{\theta \in \widehat{s}} y_{i}(i, \theta) d F(\theta)+\int_{\theta \in \bar{s}} y_{i}(i, \theta) d F(\theta), \quad \forall i .
\end{gathered}
$$

Since $e^{\prime}<e \Rightarrow \underline{w}\left(e^{\prime}, \theta\right)<\underline{w}(e, \theta)$ for any $\theta$, we have that $\theta \in \underline{s}^{\prime} \Rightarrow \theta \in \underline{s}$. Furthermore, since $(\widehat{s} \cup \underline{s} \cup \bar{s})=[\underline{\theta}, \bar{\theta}]$, we also have that $\theta \in(\widehat{s} \cup \bar{s}) \Rightarrow \bar{\theta} \in\left(\widehat{s}^{\prime} \cup \bar{s}^{\prime}\right)$, which is equivalent to $(\widehat{s} \cup \bar{s}) \subseteq\left(\widehat{s}^{\prime} \cup \bar{s}^{\prime}\right)$. However, since $\bar{w}(i, \theta)$ does not depend on $e$, we have that $\bar{s}=\bar{s}^{\prime}$ and $\widehat{s} \subseteq \widehat{s}^{\prime}$, which together with $y_{i}(i, \theta)>0$ and $\beta>0$ implies (A1). Also note that the inequality in (A1) is strict whenever $\left(\underline{s}-\underline{s}^{\prime}\right) \neq \emptyset$.

Using (8), condition related to point b) above is equivalent to:

$$
i^{\prime}<i \Rightarrow \int_{\theta \in \underline{s}^{\prime}} \widetilde{w}_{e}(e, \theta) d F(\theta) \geq \int_{\theta \in \underline{s}} \widetilde{w}_{e}(e, \theta) d F(\theta), \quad \forall e
$$


Since $i^{\prime}<i \Rightarrow \beta y\left(i^{\prime}, \theta\right)<\beta y(i, \theta)$ for any $\theta$, then $\theta \in \underline{s} \Rightarrow \theta \in \underline{s}^{\prime}$, which is equivalent to $\underline{s} \subseteq \underline{s}^{\prime}$. This, together with $\widetilde{w}_{e}(e, \theta)>0$, implies (A2). Also note that the inequality in $(\mathrm{A} 2)$ is strict whenever $\left(\underline{s}^{\prime}-\underline{s}\right) \neq \emptyset$.

Q.E.D.

\section{A.2 Proof of Result 3}

Result 3 states that the equilibrium internal and external investments by the manager are non-increasing and non-decreasing in $p^{f}$, respectively. Technically, the manager's expected payoff function (6) is supermodular in $(i,-e)$ and has increasing differences in $\left(i,-e ;-p^{f}\right)$.

Proof While the first part of Result 3 (i.e. (6) is supermodular in $(i,-e)$ ) has already been proved in Section A.1, we must show now that (6) has increasing differences in $\left(i,-e ;-p^{f}\right)$. By definition, increasing differences means that increasing a parameter raises the marginal return to activities.

First, note that (6)'s increasing differences in $i$ and $-p^{f}$, implies that decreasing $p^{f}$ raises the investment $i$ 's marginal return. More formally (and using (7)), (6) has increasing differences in $i$ and $-p^{f}$ if and only if:

$$
\begin{gathered}
p^{f \prime}<p^{f} \Rightarrow \beta \int_{\theta \in \widehat{s}^{\prime}} y_{i}(i, \theta) d F(\theta)+\int_{\theta \in \bar{s}^{\prime}} y_{i}(i, \theta) d F(\theta) \geq \\
\beta \int_{\theta \in \widehat{s}} y_{i}(i, \theta) d F(\theta)+\int_{\theta \in \bar{s}} y_{i}(i, \theta) d F(\theta), \quad \forall i
\end{gathered}
$$

where now $\widehat{s}^{\prime}=\widehat{s}\left(\cdot, p^{f \prime}\right)$ and $\bar{s}^{\prime}=\bar{s}\left(\cdot, p^{f \prime}\right)$. Since $p^{f \prime}<p^{f} \Rightarrow \underline{w}\left(e, \theta, p^{f \prime}\right)<\underline{w}\left(e, \theta, p^{f}\right)$ for any $e$ and any $\theta$, then $\theta \in \underline{s}^{\prime} \Rightarrow \theta \in \underline{s}$. Hence, $\theta \in(\widehat{s} \cup \bar{s}) \Rightarrow \theta \in\left(\widehat{s}^{\prime} \cup \bar{s}^{\prime}\right)$, which is equivalent to $(\widehat{s} \cup \bar{s}) \subseteq\left(\widehat{s}^{\prime} \cup \bar{s}^{\prime}\right)$. Moreover, since $\bar{w}\left(i, \theta, p^{f \prime}\right)<\bar{w}\left(i, \theta, p^{f}\right)$, we also have that $\bar{s} \subseteq \bar{s}^{\prime}$. Thus, taking into account that $y_{i}(i, \theta)>0$ and $0<\beta<1$, (A3) is satisfied. Also note that the inequality in (A3) is strict whenever $\left(\underline{s}-\underline{s}^{\prime}\right) \neq \emptyset$ or $\left(\bar{s}^{\prime}-\bar{s}\right) \neq \emptyset$ (or both).

Second, consider instead (6)'s increasing differences in $-e$ and $-p^{f}$. This implies that increasing $p^{f}$ raises the investment $e$ 's marginal return. More formally (and using (8)), (6) has increasing differences in $-e$ and $-p^{f}$ (or, equivalently, in $e$ and $p^{f}$ ) if and only if:

$$
p^{f \prime}>p^{f} \Rightarrow \int_{\theta \in \underline{s}^{\prime}} \widetilde{w}_{e}(e, \theta) d F(\theta) \geq \int_{\theta \in \underline{s}} \widetilde{w}_{e}(e, \theta) d F(\theta), \quad \forall e
$$

where $\underline{s}^{\prime}=\underline{s}\left(\cdot, p^{f \prime}\right)$. Since $p^{f \prime}>p^{f} \Rightarrow \underline{w}\left(e, \theta, p^{f \prime}\right)>\underline{w}\left(e, \theta, p^{f}\right)$ for any $e$ and any $\theta$, then $\theta \in \underline{s} \Rightarrow \theta \in \underline{s}^{\prime}$, which is equivalent to $\underline{s} \subseteq \underline{s}^{\prime}$. This, together with $\widetilde{w}_{e}(e, \theta)>0$, implies (A4). Also note that the inequality in (A4) is strict whenever $\left(\underline{s}^{\prime}-\underline{s}\right) \neq \emptyset$. Q.E.D. 


\section{A3. Proof of Result 5}

Result 5 states that the equilibrium internal and external investments by the manager are non-decreasing and non-increasing in $p^{m}$, respectively. Technically, the manager's expected payoff function (6) is supermodular in $(i,-e)$ and has increasing differences in $\left(i,-e ; p^{m}\right)$.

Proof Once again, the first part of Result 5 (i.e. (6) is supermodular in $(i,-e)$ ) has already been proved in Section A.1. Thus, we must show here that (6) has increasing differences in $\left(i,-e ; p^{m}\right)$.

Consider first (6)'s increasing differences in $i$ and $p^{m}$. This implies that increasing $p^{m}$ raises the investment $i$ 's marginal return. More formally (and using (7)), (6) has increasing differences in $i$ and $p^{m}$ if and only if:

$$
\begin{gathered}
p^{m \prime}>p^{m} \Rightarrow \beta \int_{\theta \in \widehat{s}^{\prime}} y_{i}(i, \theta) d F(\theta)+\int_{\theta \in \bar{s}^{\prime}} y_{i}(\bar{i}, \theta) d F(\theta) \geq \\
\beta \int_{\theta \in \widehat{s}} y_{i}(i, \theta) d F(\theta)+\int_{\theta \in \bar{s}} y_{i}(i, \theta) d F(\theta), \quad \forall i
\end{gathered}
$$

where now $\widehat{s}^{\prime}=\widehat{s}\left(\cdot, p^{m \prime}\right)$ and $\bar{s}^{\prime}=\bar{s}\left(\cdot, p^{m \prime}\right)$. Since $p^{m \prime}>p^{m} \Rightarrow \underline{w}\left(e, \theta, p^{m \prime}\right)<$ $\underline{w}\left(e, \theta, p^{m}\right)$ for any $e$ and any $\theta$, then $\theta \in \underline{s}^{\prime} \Rightarrow \theta \in \underline{s}$. Hence, $\theta \in(\widehat{s} \cup \bar{s}) \Rightarrow \theta \in\left(\widehat{s}^{\prime} \cup \bar{s}^{\prime}\right)$, which is equivalent to $(\widehat{s} \cup \bar{s}) \subseteq\left(\widehat{s}^{\prime} \cup \bar{s}^{\prime}\right)$. Moreover, since $\bar{w}\left(i, \theta, p^{m \prime}\right)<\bar{w}\left(i, \theta, p^{m}\right)$, we also have that $\bar{s} \subseteq \bar{s}^{\prime}$. Thus, taking into account that $y_{i}(i, \theta)>0$ and $0<\beta<1$, (A5) is satisfied. Also note that the inequality in (A5) is strict whenever $\left(\underline{s}-\underline{s}^{\prime}\right) \neq \emptyset$ or $\left(\bar{s}^{\prime}-\bar{s}\right) \neq \emptyset$ (or both).

Second, consider instead (6)'s increasing differences in $-e$ and $p^{m}$. This implies that increasing $p^{m}$ decreases the investment $e$ 's marginal return. More formally (and using (8)), (6) has increasing differences in $-e$ and $p^{m}$ if and only if:

$$
p^{m \prime}<p^{m} \Rightarrow \int_{\theta \in \underline{s}^{\prime}} \widetilde{w}_{e}(e, \theta) d F(\theta) \geq \int_{\theta \in \underline{s}} \widetilde{w}_{e}(e, \theta) d F(\theta), \quad \forall e
$$

where now $\underline{s}^{\prime}=\underline{s}\left(\cdot, p^{m \prime}\right)$. Since $p^{m \prime}<p^{m} \Rightarrow \underline{w}\left(e, \theta, p^{m \prime}\right)>\underline{w}\left(e, \theta, p^{m}\right)$ for any $e$ and any $\theta$, we have that $\theta \in \underline{s} \Rightarrow \theta \in \underline{s}^{\prime}$, which is equivalent to $\underline{s} \subseteq \underline{s^{\prime}}$. This, together with $\widetilde{w}_{e}(e, \theta)>0$, implies (A6). Also note that the inequality in (A6) is strict whenever $\left(\underline{s}^{\prime}-\underline{s}\right) \neq \emptyset$.

Q.E.D.

\section{References}

Almazan, A., And J. Suarez [2003], "Entrenchment and Severance Pay in Optimal Governance Structures," Journal of Finance, 58, 519-547.

Becker, G. [1964], Human Capital: A Theoretical and Empirical Analysis with Special Reference to Education, The University of Chicago Press: Chicago. 
Binmore, K. [1987], "Perfect Equilibria in Bargaining Models," in: K. Binmore e P. Dasgupta (eds.), The Economics of Bargaining, Blackwell: Oxford.

-- , A. Rubinstein, And A. Wolinsky [1986], "The Nash Bargaining Solution in Economic Modelling," RAND Journal of Economics, 17, 176-188.

CAI, H. [2003], "A Theory of Joint Asset Ownership," RAND Journal of Economics, 34, 63-77.

Callahan, M.B. [1985], "Post-Employment Restraint Agreements: A Reassessment," University of Chicago Law Review, 52, 703-728.

Che, Y.-K., And T.-Y. Chung [1999], "Contract Damages and Cooperative Investments," RAND Journal of Economics, 30, 84-105.

- -, AND D.B. Hausch [1999], "Cooperative Investments and the Value of Contracting," American Economic Review, 89, 125-147.

Chor, A. [2004], "Golden Parachute as a Compensation Shifting Mechanism," Journal of Law, Economics, and Organization, 20, 170-191.

Chung, T.-Y. [1992], "On the Social Optimality of Liquidated Damage Clauses: An Economic Analysis," Journal of Law, Economics, and Organization, 8, 280-305.

Edlin, A.S., And S. Reichelstein [1996], "Holdups, Standard Breach Remedies, and Optimal Investment," American Economic Review, 86, 478-501.

Fella, G. [2005], "Termination Restrictions and Investment in General Training," European Economic Review, 49,1479-1499.

Gibbons, R. [1998], "Incentives in Organizations," Journal of Economic Perspectives, 12, 115-132.

Grout, P.A. [1984], "Investment and Wages in the Absence of Binding Contracts: A Nash Bargaining Approach," Econometrica, 52, 449-460.

Harris, E. [1990], "Antitakeover Measures, Golden Parachutes, and Target Firm Shareholder Value," RAND Journal of Economics, 21, 614-625.

Hart, O., AND J. Moore [1988], "Incomplete Contracts and Renegotiation," Econometrica, $56,755-785$.

Jensen, M., And R.S. Ruback [1983], "The Market for Corporate Control: The Scientific Evidence," Journal of Financial Economics, 11, 5-50.

Kessler, A.S., And C. Lülfesmann [2006], "The Theory of Human Capital Revisited: On the Interaction of General and Specific Investments," Economic Journal, 116, 903-923.

Lambert, L.A., AND D.F. Larcker [1985], "Golden Parachutes, Executives Decision-Making, and Shareholder Wealth," Journal of Accounting and Economics, 7, 179-203.

Lefanowicz, C., J. Robinson, And R. Smith [2000], "Golden Parachutes and Managerial Incentives in Corporate Acquisition: Evidence from the 1980s and 1990s," Journal of Corporate Finance, 46, 215-239.

Long, B.S. [2005], "Protecting Employer Investment in Training: Noncompetes vs. Repayment Agreements," Duke Law Journal, 54, 1295-1320.

MacLeod, W.B., and J.M. Malcomson [1993], "Investments, Holdup, and the Form of Market Contracts," American Economic Review, 83, 811-837.

- -, AND - - [1995], "Contract Bargaining with Symmetric Information," Canadian Journal of Economics, 28, 336-367.

Malcomson, J.M. [1997], "Contracts, Hold-Up, and Labor Markets," Journal of Economic Literature, 35, 1916-1957.

Milgrom, P., And C. Shannon [1994], "Monotone Comparative Statistics," Econometrica, $62,157-180$. 
Mogavero, D.J., And M.F. Toyne [1995], "The Impact of Golden Parachutes on Fortune 500 Stock Returns: A Reexamination of the Evidence," Quarterly Journal of Business and Economics, 34, 30-38.

Muthoo, A. [1999], Bargaining Theory with Applications, Cambridge University Press: Cambridge.

Osborne, M.J., And A. Rubinstein [1990], Bargaining and Markets, Academic Press: San Diego.

Segal, I.R., And M.D. Whinston [2000], "Exclusive Contracts and Protection of Investments," RAND Journal of Economics, 31, 603-633.

Shaked, A., And J. Sutton [1984], "Involuntary Unemployment as a Perfect Equilibrium in a Bargaining Model," Econometrica, 52, 1351-1364.

Spier, K.E., And M.D. Whinston [1995], "On the Efficiency of Privately Stipulated Damages for Breach of Contract: Entry Barriers, Reliance, and Renegotiation," RAND Journal of Economics, 26, 180-202.

Williamson, O.E. [1984], "Corporate Governance," Yale Law Journal, 93, 1197-1230.

- - [1985], The Economic Institutions of Capitalism, Free Press: New York.

Nicola Meccheri

Department of Economics

University of Pisa

Via C. Ridolfi, 10

I-56124 Pisa (PI)

Italy

E-mail:

meccheri@ec.unipi.it 